Doc. dr Fehim Rošić

\title{
Socio-emocionani razvoj malog djeteta
}

Sažetak

Socio-emocionalni razvoj, zajedno sa kognitivnim razvojem, predstavlja kod djece ono područje koje je najbitnije za razumijevanje specifičnosti brojnih pitanja vezanih za ponašanje $i$ ukupno funkcionisanje $u$ ovom razvojnom periodu. $U$ području socioemocionalnog razvoja, pored razvoja $i$ diferencijacije emocija, značajno je $i$ pitanje razvoja temperamenta. Pojedine osobine temperamenta su različito stabilne prema promjenama. Tako je npr., uočeno da ritam aktivnosti $i$ raspoloženje, kao osobine, relativno uveliko variraju kroz starosne dobi, dok su nivo aktivnosti, te otvorenost ili sramežljivost relativno stabilne. U socio-emocionalnom razvoju značajno je pitanje doživljavanja sebe (svijest o sebi, jasvijest, samosvijest). Negdje se ovo pitanje razmatra u sklopu kognitivnog razvoja, budući da zadire u područje svijesti, saznanja, ali ono uvijek ima socijalnu dimenziju i rezultat je interakcijskih, interpersonalnih, dakle, socijalnih relacija. Djeca pokazuju značajne individualne razlike u svojim emocionalnim vezama sa odraslima, odnosno, u emocionalnoj vezanosti, koja relativno konstantno povezuje dijete sa odraslom osobom, a u prvom redu sa roditeljima $i$ drugim važnim osobama u njegovoj okolini. U tijesnoj vezi sa emocionalnom vezanošću je $i$ odvajanje djece i strah od nepoznatih osoba. U različitim kulturama djeca reagiraju na odvajanje, uglavnom, na isti način, ali postoje razlike u dobi kada im se to dešava.

Ključne riječi: osnovna osjećanja, diferencijacija osjećanja, temperament, periodizacija razvoja, sramežljivost, doživljavanje sebe, self, emocionalna vezanost, odvajanje 


\section{Uvod}

Čovjekov razvoj od rođenja do zrelosti i dalje, odvija se u permanentnoj interakciji individua - okolina. Taj razvoj je kompleksan, specifičan i razlikuje se u odnosu na razvoj drugih živih bića. U biljnom svijetu razvoj sadnice u izraslo drvo je kontinuiran, teče ravnomjerno i linearno: jedan god za jednu godinu. Kod vodozemaca $\mathrm{i}$ insekata $\mathrm{u}$ razvoju se javljaju krupne metamorfoze $\mathrm{i}$ razvoj nema linearan tok: jedna siva larva na kraju postaje leptir blistavih boja, žaba prođe kroz stadij punoglavca i dr.

Kod čovjeka razvoj nije ni linearan, niti prolazi kroz metamorfoze, već je taj razvoj stepenast, to je razvoj na mahove i liči na penjanje uz stepenice: jedno vrijeme nalazimo se na jednoj stepenici, a zatim zakoračimo i popnemo se na slijedeću. U tom stepenastom razvoju javljaju se periodi kada se mora dostići jedan stepen razvoja, kada sposobnosti i druge osobine ličnosti omogućuju nastanak razvojno višeg oblika ponašanja. Ti prelazi predstavljaju kritične periode, pa možemo govoriti o krizama razvoja u djetinjstvu i mladosti, odnosno, o razvojnim krizama. Čovjek, kao društveno biće, osim anatomsko-fizioloških, ima i brojne druge specifičnosti koje ga kvalitativno izdvajaju od životinjskih vrsta. Te razlike su evidentne posebno u kognitivnoj, emocionalnoj i socijalnoj sferi čovjekovog života i funkcioniranja.

Socio-emocionalni razvoj, zajedno sa kognitivnim razvojem, predstavlja kod djece ono područje koje je najbitnije za razumijevanje specifičnosti brojnih pitanja vezanih za ponašanje i ukupno funkcionisanje $\mathrm{u}$ ovom razvojnom periodu. Iako se $\mathrm{u}$ razvojnoj psihologiji najčešće govori posebno o socijalnom, a posebno o emocionalnom razvoju, ova dva područja razvoja su toliko isprepletena i u stvarnosti nerazdvojiva, međusobno utječu jedno na drugo tako snažno da ih je, ustvari, teško razaznati kao zasebna područja. Zapravo, socio-emocionalne i kognitivne razlike i specifičnosti $u$ ovom periodu razvoja $u$ odnosu na odrasle osobe, upravo su presudne za sve one brojne posebnosti kojima se ponašanje djece bitno izdvaja i razlikuje u odnosu na ponašanje odraslih. Te posebnosti, uvjetovane najviše socio-emocionalnim razlikama djeteta $\mathrm{u}$ odnosu na odraslu osobu odražavaju se i ispoljavaju u svim aspektima ponašanja, reagovanja, opažanja i doživljavanja, a posebno 
u području samopoimanja, samosvijesti, svijesti o sebi ili slici o sebi kod djece.

\section{Osobenosti socio-emocionalnog razvoja malog djeteta}

U periodizaciji razvoja periodom malog djeteta označavaju se prve dvije godine dječijeg života. Prvi oblici emocionalnog života javljaju se mnogo ranije nego što se nekad mislilo. Već nakon prvog mjeseca života dijete, na određen način, izražava neke vlastite osjećaje i pokazuje određene specifične reakcije na osjećaje drugih. Ranije se vjerovalo da djeca nemaju «stvarnih» osjećaja, zapažalo se da ona plaču ako su gladna i da se smiju kad ugledaju poznato drago lice, ali se vjerovalo da to nisu prava osjećanja, već jednostavni i relativno primitivni refleksi. Takvo uvjerenje imalo je nekad vrlo štetne konzekvence: smatralo se da, zbog toga, ne treba posebno voditi računa o dešavanjima u dječijoj okolini, pa čak da se moglo odustati od davanja narkoze pri manjim hirurškim zahvatima na ovom uzrastu.

Međutim, novija istraživanja su pokazala da i veoma mala djeca mogu, ne samo izražavati tzv., osnovne osjećaje (radost, gnjev, iznenađenje, strah, tuga, gnušanje), već i reagirati na te podražaje. Ovi primarni osjećaji imaju značaj i vrijednost za preživljavanje djeteta, za socijalne ciljeve koji su usmjereni na druge osobe i predstavljaju osnovu za razvoj kasnijih tzv., izvedenih osjećaja (npr., stid, krivnja, ljubomora). Novorođenče tokom razvoja postaje sve uspješnije u upravljanju situacijama koje bude i izazivaju osjećaje. Osjećaji vremenom bivaju u sve većoj mjeri obojeni socijalnim faktorima, djeca postaju sve uspješnija u tumačenju emocionalnih manifestacija drugih ljudi.

Diferencijacija osjećanja počinje kod djeteta vrlo rano, nakon njegovog rođenja. Već u prvim danima ono je u stanju da reagira na iznenadne zvukove ili nečije naglo približavanje njegovom licu začuđenim izrazom lica ili plačem. Nakon određenog vremena $u$ emocionalnom životu djeteta dolazi do dalje diferencijacije osjećanja.

Dijete svoja osjećanja na ovom uzrastu izražava i glasom i pokretima. Međutim, iste emocionalne reakcije mogu imati različito značenje. Tako se npr., kod novorođenčeta mogu zapaziti različite vrste plača, (Hwang P., Nilsson B, 2000. str. 125.), kao: 
- «plač gladi» (sastoji se iz kratkih učestalih vriskova s kratkim pauzama za udisanje),

- «plač neprijatnosti» (dugotrajniji plač, više intonacije, s dužim pauzama)

Slično je i sa drugim emocijama.Tako se npr., smijeh javlja vrlo rano, tokom prvih dana nakon rođenja, obično tokom hranjenja, refleksno, dok se prvi socijalni osmijeh javlja u dobi od oko 6 sedmica, a na uzrastu od 3 mjeseca osmijeh postaje širi i može preći u smijeh. Dakle, diferencijacija i razvoj osjećanja se može pratiti i analizirati s više aspekata:

- kvantitativno, hronološki (prati se kada se javljaju pojedina osjećanja) i

- kvalitativno (kakve su razlike u emocionalnim reakcijama i kakvo je njihovo značenje u interpersonalnim socijalnim relacijama).

U području socio-emocionalnog razvoja, pored razvoja i diferencijacije emocija, značajno je i pitanje razvoja temperamenta. Pošto temperament obuhvata osobenosti reagiranja osobe $u$ emocionalnim situacijama, ovo pitanje je značajno sa stanovišta razumijevanja traume kod djece i adolescenata. Američki psiholozi Aleksandar Tomas i Stela Čis (Alexander Thomas, Stella Chess) smatraju da se individualne manifestacije temperamenta mogu primijetiti već nekoliko sedmica nakon rođenja i to praćenjem reakcija dojenčeta na stres.

Davno je uočeno da od načina na koji dijete reagira na različite situacije, zavise reakcije okoline prema djetetu, odnosno, reakcije odraslih osoba prema djetetu. $\mathrm{Na}$ osnovu tog instrumentalnog relacijskog svojstva temperamenta, mnogi su smatrali da je temperament rezultat interakcije između odraslih i djece, dakle, da je naučena, stečena crta ličnosti. Međutim, brojna istraživanja su pokazala da su mnoge osobine temperamenta urođene. 


\section{Bitna obilježja toka socio-emocionalnog razvoja malog djeteta}

Tokom prvih dana i mjeseci kod novorođenčeta razlikujemo slijedećih devet karakterističnih crta, koje određuju prirodu njihovog ukupnog socio-emocionalnog ponašanja i funkcioniranja:

1) nivo aktivnosti: neprekidno su u pokretu, aktivna su i ubrzana,

2) redovitost: neka djeca uredno spavaju, jedu, imaju stolicu u određeno vrijeme, dok su druga djeca u tome znatno manje predvidiva,

3) radoznalost - izbjegavanje: neka djeca se lako oduševe, ushićena su svime novim, druga ne ispoljavaju naglašenu radoznalost, izbjegavaju, povlače se,

4) prilagođavanje: nekoj djeci su promjene zabavne, lako i brzo se prilagođavaju, dok su druga, pak, pred promjenama žalosna, utučena, plaču,

5) intenzitet u reakcijama: neka djeca se glasno smiju ili viču, dok su druga mirnija u svojim reakcijama,

6) reakcijski prag: neka djeca su vrlo osjetljiva na svjetlost, zvuk, lako se bude, dok druga ne reagiraju na ove pojave sve dok one ne budu izražene sa vrlo visokim intenzitetom,

7) iritabilitet: izvjesna djeca su skoro uvijek vesela i otvorena, druga izgledaju kronično žalosna,

8) distrakcija: reakcije djece na uskraćivanje su različite.Ako se npr., djetetu uskrati jelo, neka djeca će na to zaboraviti ako im se privuče pažnja nečim drugim (pjesmom, igračkom), druga djeca, pak, nastavljaju s protestom sve dok ne dobiju jelo i ne dopuštaju da ih se nečim zabavi,

9) obim interesovanja: neka se djeca mogu satima igrati s jednom igračkom, a druga brzo ispuštaju ono što imaju u ruci i žele započeti nečim novim. (Hwang P., Nilsson B., 2000. str. 126.).

Pojedine osobine temperamenta su različito stabilne prema promjenama. Tako je npr., uočeno da ritam aktivnosti i raspoloženje, kao osobine, relativno uveliko variraju kroz starosne dobi, dok su nivo aktivnosti, te otvorenost ili sramežljivost relativno stabilne.

Sa stanovišta značaja socio-emocionalnog razvoja djeteta bitna je osobina sramežljivosti ili stidljivosti. Sramežljiva djeca se u ranoj 
dobi lako iritiraju, a kasnije u životu negativno reagiraju na strane osobe i na stvari na koje nisu navikli. Ovakvoj djeci je potrebno više vremena za prilagođavanje, potrebna im je snažnija socijalna podrška i šira socijalna mreža. Sramežljivost ili stidljivost treba razlikovati od nesigurnosti: ako je osjećaj nesigurnosti izazvan situacijom izvana, onda je to nesigurnost. Tako npr., većina djece je stidljiva u izvjesnim situacijama, prije svega u prisustvu nepoznatih osoba i tada se osjećaju nesigurnima, dok su u drugim situacijama sigurna. Stidljivost je, pak, unutrašnji oblik nesigurnosti. Stidljivost se, takođe, dovodi u vezu sa poniženjem, stidom i sramom, što upućuje na značajnu socijalnu dimenziju stidljivosti ili sramežljivosti.Porijeklo i izvor stidljivosti se nalazi u samoj osobi, ali se prema vani manifestira $u$ interakciji s drugim ljudima.Stidljivo dijete ima lošu sliku o sebi, nisku samosvijest i nisko samopouzdanje.

Neka istraživanja pokazuju da se, otprilike, svako deseto dijete rodi sa tendencijom stidljivosti i povučenosti, ali isto tako da stidljiva djeca u najvećem broju slučajeva imaju najmanje jednog stidljivog roditelja, što upućuje na značaj nasljednih momenata. Stidljivost se može zapaziti vrlo rano: već u dobi od 4 mjeseca. Stidljiva djeca reaguju intenzivnije na vanjske podražaje. Na uzrastu od jedne godine ova djeca su plašljivija od druge djece i nesigurnija u susretu s nepoznatim stvarima i osobama. Ova djeca imaju bržu frekvenciju rada srca i luče više adrenalina, koji je prevashodno stresni hormon. Napetost mišića im je u području vrata veća nego kod druge djece, što doprinosi da im je glas više napet i napregnut, pa zbog toga okolina drukčije reaguje na takvu djecu.

$\mathrm{U}$ socio-emocionalnom razvoju značajno je pitanje doživljavanja sebe (svijest o sebi, ja-svijest, samosvijest). Negdje se ovo pitanje razmatra u sklopu kognitivnog razvoja, budući da zadire u područje svijesti, saznanja, ali ono uvijek ima socijalnu dimenziju i rezultat je interakcijskih, interpersonalnih, dakle, socijalnih relacija. Doživljavanje sebe samog razvija se postepeno. Tokom prvih mjeseci djeca nisu svjesna sama sebe, tek negdje sa 12 mjeseci svjesna su da je neko drugo dijete «posebna» osoba. Potvrdu o ovom dalo je jedno istraživanje provedeno na djeci uzrasta 9-24 mjeseca (Hwang P., Nilsson B.2000. str. 126.). 
Na lice djeteta je stavljena bojom jedna crvena mrlja, a zatim bi pred takvo dijete bilo stavljeno ogledalo. Ako su se djeca hvatala tada za mrlju (npr., za obraz), bilo je jasno da su znala da gledaju same sebe u ogledalu. Niti jedno dijete mlađe od 12 mjeseci nije reagovalo na crvenu mrlju, ali je najveći broj njih između 12 i 24 mjeseca reagiralo.

Svjesnost o sebi samome, kao osobi, značajan je momenat socio-emocionalnog razvoja. Snažne emocionalne reakcije u dobi 2-4 godine razvijaju se upravo zato što dijete počinje biti svjesno da je ono taj koga neko sprječava ili tuče, voli ili odbacuje i sl. Zato se broj svakodnevnih konflikata djece i roditelja povećava tokom druge godine života. Isto tako, osjećanje srama ili ponosa, doživljavanje ovih osjećanja i ispoljavanje odgovarajućih reakcija, mogući su samo ako dijete ima shvatanje sebe samog.

Američki psihijatar Danijel Štern (Daniel N. Stern) smatra poimanje sebe («sense of self») pitanjem od centralne važnosti u ovoj fazi razvoja. On self opisuje kao doživljavanje sebe samoga i smatra da se self razvija jednom razvojnom linijom koja se sastoji od pet djelimično preklapajućih etapa:

1) buđenje self-a (0-2 mjeseca): osjećaj samog sebe kod dojenčeta se razvija u interakciji s okolinom,

2) jezgreni self (2-6 mjeseci): dojenče se razvija kao socijalno biće kroz dva aspekta: "sam i drugi,» odnosno, «sam s drugima».,

3) subjektivni self (7-15 mjeseci): dijete počinje shvatati da i drugi ljudi imaju svoj unutarnji život, stvara novu vrstu iskustva i socijalni osjećaj,

4) verbalni self (16-36 mjeseci): razvojem govora dijete ulazi u period gdje riječ ima jedan smisao i gdje se riječima mogu prenijeti vlastita iskustva,

5) narativni self (3 godine i dalje): dijete može opisati samog sebe, svoja osjećanja i doživljaje, u formi priče, kazivanja, naracije (Hwang P., Nilsson B, 2000. str. 129.)

Pored doživljavanja sebe ili svijesti o sebi, za razumijevanje socio-emocionalnog razvoja, bitno pitanje je i pitanje razvoja ličnosti. Ličnost, kao specifična organizacija osobina, koja se kroz vrlo složene 
procese i dinamizme formira kod pojedinca, značajna je za ukupan odnos pojedinca prema sebi za interakcijske odnose s okolinom i za ukupno ponašanje i funkcioniranje osobe

Zigmund Frojd (Sigmund Freud) je smatrao da presudan uticaj u formiranju i razvoju ličnosti imaju prve godine života, a poseban je u tome značaj majke. U ovom periodu, smatrao je on, od velike je važnosti majčino držanje prema djetetu, njen način dojenja i odvikavanja od dojenja, a u analnom stadijumu (dob 1,5-2 godine) način održavanja čistoće. I oralni i analni stadij su puni konflikata od čijeg uspješnog razrješavanja zavisi razvoj ličnosti djeteta.Ako majka ne dozvoli djetetu da siše dovoljno mnogo ili dovoljno dugo, ako prerano počne sa odvikavanjem, smatra Frojd, to može stvoriti izvjesno fiksiranje u oralnom stadijumu i ispoljiti se kasnije raznim abnormalnostima (abnormalno jedenje ili pijenje, griženje noktiju i slična oralna zadovoljenja potreba koja kompenziraju ono što se branilo u djetinjstvu). Kao odrasli «oralni» ljudi su previše velikodušni, neorganizirani, trajno kasne na sve, a takve svoje osobine najčešće poriču tako što postaju kruti u relacijama prema drugim ljudima, sarkastični i zajedljivi. Ako je majka u održavanju čistoće djeteta postupala previše kruto ili počela prerano, doći će do razvoja analno retetivne ličnosti koja prenaglašava red, urednost i tačnost ili je impulsivna i neorganizirana.

Erikson (Erik H. Erikson) je smatrao da osnovni konflikt tokom prvih godina nije usmjeren na oralno zadovoljenje, kako je smatrao Frojd, već na interakciju u kojoj se može doći do takvih iskustava. Prema Eriksonu, konflikt tokom prve godine je pitanje povjerenja nasuprot nepovjerenju: djeca nauče da vjeruju okolini, ako se ona o njima brine. U drugom stadijumu (2. godina), po Eriksonu, u centru pažnje je konflikt između autonomije s jedne, te srama $\mathrm{i}$ sumnje u samog sebe, s druge strane. Dvogodišnjak često želi sam odlučiti i ako je okolina prestroga, ili puna zabrana, nastaje osjećaj srama i nedostatnosti.

Maler-ova (Margaret Mahler) smatra da dijete u prve tri godine prolazi kroz tri različite faze razvoja:

a) autistična faza: dijete je zatvoreno samo u sebe i njegovo ponašanje je rukovođeno željom da se postigne ravnoteža, 
b) simbiotička faza: stvaranje zajedničkog svijeta između djeteta $i$ majke,

c) faza individualizacije i separacije: dijete postepeno razvija shvatanje sebe samog i način gledanja na druge ljude.Individualizacija znači da dijete razvija identitet, način gledanja na sebe samog kao na samostalno biće, a separacija da dijete izdvaja, separira druge osobe od sebe samog

Pored urođenih osobina djeteta i roditeljskih postupaka prema djetetu, posebno važan faktor u socio-emocionalnom razvoju djeteta je interakcija između roditelja i djece. Na proces interakcije značajno utječe:

1) ličnost roditelja: da bi se interakcija uspostavila i odvijala, odrasli moraju kod djeteta prepoznati njegove osjećaje i potrebe, a zatim se prema njima odrediti i postaviti na način koji odgovara potrebama djeteta, izbjegavajući stereotipe, oponašanje ili imitaciju.Postoje značajne razlike kod roditelja po pitanju osjetljivosti i sposobnosti da djeci saopće kako oni razumiju njihove osjećaje,

2) doživljaji djeteta: dijete treba osjetiti da reakcije roditelja imaju veze s njegovim vlastitim emocionalnim doživljajima, da ga roditelj razumije i prihvata. Ako roditeljsku reakciju dijete tako doživi, ono će imati osjećaj da ga se razumjelo, a time i osjećaj sigurnosti,

3) priroda kontakta: dijete se rađa sposobno da vidi i sa potrebom da traži kontakt očima već od samog rođenja. Prvi kontakt očima između djeteta i odraslog predstavlja za dijete veoma snažan emocionalni doživljaj. Priroda kontakta značajno određuje hoće li se vremenom kroz komunikaciju stvarati sve veća socijalna uzajamnost $\mathrm{u}$ interakciji. U kontaktu odraslog $\mathrm{i}$ djeteta u komunikaciji se na ovom uzrastu izmjenjuju različiti vidovi i oblici: izmjenjuju se zvukovi, izrazi lica, pokreti i kontakti pogledom.

Djeca pokazuju značajne individualne razlike $u$ svojim emocionalnim vezama $\mathrm{s}$ odraslima, odnosno, $\mathrm{u}$ emocionalnoj vezanosti, koja relativno konstantno povezuje dijete $\mathrm{s}$ odraslom osobom, a u prvom redu s roditeljima i drugim važnim osobama u njegovoj okolini. Većina djece se ponaša na takav način da, kada se 
npr., dogodi nešto neočekivano (pojavi se npr., neka strana osoba), dijete se obično želi naći u blizini roditelja. Ako roditelja tada nema u blizini, dijete plače i traži ga, a kada se odsutni roditelj vrati, dijete aktivno traži njegovu blizinu i kontakt s njima.

Međutim, jedan manji broj djece ne koristi roditelje kao osnovu sigurnosti, ambivalentni su prema roditelju, jer tada istovremeno i traže i odbijaju kontakt s roditeljem. Neka djeca, pak, u ovakvim situacijama i ne obraćaju pažnju da su roditelji odsutni, a po njihovom povratku izražavaju prema njima odbojnost. Pokazalo se da su, u najvećem broju slučajeva, majke ambivalentne i odbojne djece neosjetljive na dječije signale, prilično rijetko imaju s djetetom tople tjelesne kontakte i rijetko iskazuju pozitivne osjećaje prema djetetu. One se rijetko igraju s djecom, a najveći dio vremena koje provode $\mathrm{s}$ djetetom, posvećuju njegovoj tjelesnoj njezi.

U tijesnoj vezi s emocionalnom vezanošću je i odvajanje djece i strah od nepoznatih osoba. Prve reakcije na odvajanje dijete pokazuje između 6 i 9 mjeseci (obično oko 8 mjeseci). U različitim kulturama djeca reagiraju na odvajanje, uglavnom, na isti način, ali postoje razlike $\mathrm{u}$ dobi kada im se to dešava.Tako npr., djeca $\mathrm{u}$ Gvatemali ispoljavaju strah od odvajanja $u$ istoj dobi kad i djeca Švedske (u dobi od 8 mjeseci), a djeca u Ugandi počinju ovakve reakcije ispoljavati već sa 6 mjeseci (Hwang P., Nilsson B., 2000. str. 137.).

Treba razlikovati trenutnu od duže odvojenosti djeteta od roditelja. $\mathrm{Na}$ dužu odvojenost dijete je posebno osjetljivo u dobi između 6 mjeseci i 3 do 4 godine. Reakcije djeteta na dužu odvojenost u ovom razdoblju najprije uključuju žalost i očaj, zatim gnjev i otpor, a potom jedno «prilagođavanje» koje je, ustvari, praćeno intenzivnim osjećajem tjeskobe i nesigurnosti, koje iz temelja mijenja djetetovo ponašanje, čini ga krajnje nesigurnim, uz brojne tjelesne simptome.

\section{Literatura}

1. Ajduković M. et. al.: Prevencija poremećaja u ponašanju kod djece stradalnika rata, Zagreb, 1995.

2. Anić N.: Praktikum iz kognitivne i bihevioralne terapije III, Zagreb, 1990. 
3. Capone C.: Majka i dete, Beograd, 1977.

4. Čaušević R.: Trauma i škola, Zenica, 2003.

5. Čuturić N.: Zabrinjava me moje dijete, Zagreb, 1995.

6. Daneš V.: Dijete, vanjski svijet i psihički poremećaji, Zenica 2003.

7. Eljkonjin D. B.: Psihologija dečje igre, Beograd, 1990.

8. Hwang P., Nilsson B.: Razvojna psihologija, Sarajevo, 2000.

9. Kamenov E.: Predškolska pedagogija, Sarajevo, 2002.

10. Miharija Ž., Leko - Kolbah A.: Pomozimo djeci stradaloj $u$ ratu - priručnik za psihologe, Zagreb, 1994.

11. Milosavljević B. et al.: Djeca u ratu i poslije rata, Banjaluka, 2000.

12. Mitrović D.: Predškolska pedagogija, Sarajevo, 2002.

13. Pehar - Zvačko L.: Razvojni problemi djece, Sarajevo, 2002.

14. Rošić F.: Kako pomoći djetetu koje se boji, Zenica, 2003.

15. Valon A.: Psihički razvoj deteta, Beograd, 1999.

16. Vasta R. et. al.: Dječja psihologija - moderna znanost, Jastrebarsko, 1998.

17. Vodak P., Šulc A.: Mane i poremećaji ponašanja u dječijem dobu, Sarajevo, 1966. 


\section{SOCIO-EMOTIONAL DEVELOPMENT OF YOUNG CHILDREN}

\section{SUMMARY}

Socio-emotional development of children represents, along with cognitive development, an area which is very significant for understanding specific qualities of numerous questions associated to behaviour and overall functioning during this development period. In the area of socio-emotional development apart from development and diferentation of emotions,important is the question of temperament development. Some temperament qualities are differently stabile towards changes. For example, it has been noticed that activity rhytm and mood as characteristics have relatively high degree of variety depending on the age, while levels of activity, along with shighness and communicativity, are relatively stabile.

Question of self-perception (self-confidence) is significant in socio-emotional development. Sometimes this question is analysed as a part of cognitive development because it affects the area of conciousness (comprehension), but always contains social dimensons and is a result of interactive, interpersonal, social relations. Children manifest significant individual differences in their emotional connections with adults, refering to emotional attachment which has a relative consistency in childs connection to parents and other important persons in childs enviroment. Emotional development is very closely related to child's separation and the fear or an unfamiliar person.Children respond to separation mostly in the same way in different cultures, but there exists difference regarding the age when the separation occurs.

Key words: basic emotions, diferentation of emotions, temperament, periodisation of development, shighness, selfperception, emotional attachment, separation. 


\section{نمو الصبي الاجتماعي والعاطفي}

\section{خلاصة البحث}

يمثّل النمو الاجتماعي والعاطفي بالإضافة إلى النمو الإدراكي لدى الأطفال أهمَّ بحال لفهم

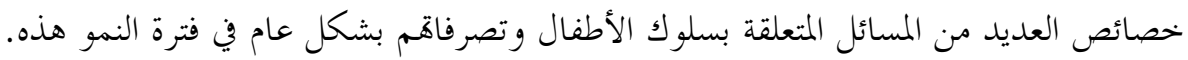

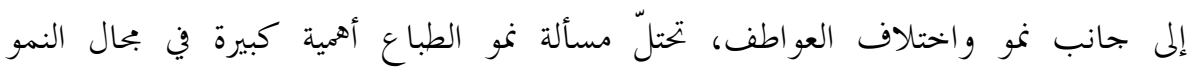
الاجتماعي و العاطفي.

بعض صفات الطباع يختلف ثباها حسب التغيرات، فعلى سبيل المثال، الملاحظ أن التحرك

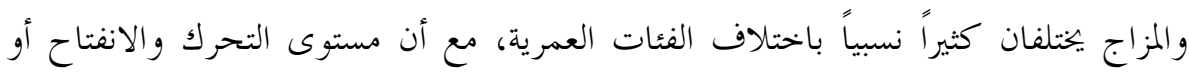
الخجل ثابتة نسبياً. في بحال النمو الاجتماعي والعاطفي تعتبر مسألة إدراك الذات مهمةً.

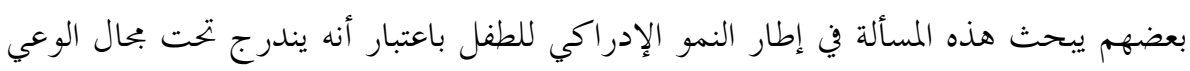

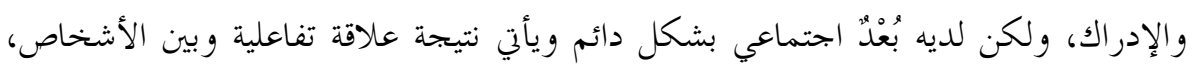
أي نتيجة علاقة اجتماعية.

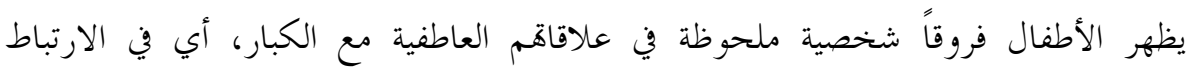

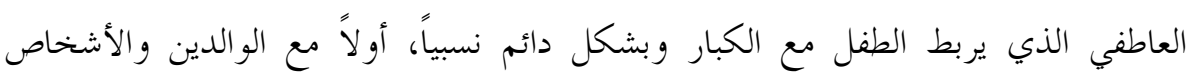
المُهمِّين المتو اجدين في محيطهم. إن فصل الأولاد و الخوف من الأشخاص البحهولين متعلق بشدة بالارتباط العاطفي. في الثقافات

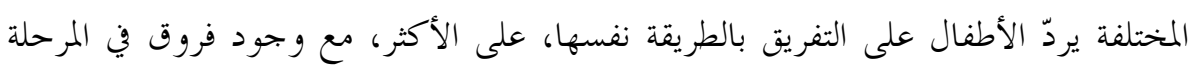
العمرية التي يتم فيها ذلك. 